\title{
ANALISIS STRATEGI PEMASARAN DAN PELAYANAN DALAM UPAYA PENINGKATAN KUALITAS DAYA SAING BIRO PERJALANAN HAJI DAN UMROH PROSPEKTIF EKONOMI SYARI'AH (Studi Pada PT. Makkah Multazam Safir dan Al Madinah)
}

\author{
H. M. Nasrun Nazaruddin
}

Universitas Islam Negeri Raden Intan Lampung

Email: nasrunnazaruddin@gmail.com

\author{
Rahmat Hidayat \\ Universitas Islam Negeri Raden Intan Lampung \\ Email: hidayatrahmat677@gmail.com \\ Ricco Andreas \\ Universitas Lampung \\ Email: andreasricco@gmail.com
}

\begin{abstract}
Hajj becomes part of the fifth pillar of faith after the creed, prayer, fasting, and alms. Hajj and Umrah are required for those who are powerful (capable), each man or woman once in a lifetime. In general, the Indonesian Muslim community performs the Hajj and Umrah to the Grand Mosque in Makkah through Hajj and Umrah travel. The number of devotees of Umrah pilgrims in Indonesia is so much the main attraction for entrepreneurs in the field of travel. This study uses a qualitative approach and is a type of field research (Field Research) and compares the pilgrimage and umrah services of PT. Makkah Multazam Safir and AlMadinah Tour \& Travel in Bandar Lampung which together are business entities that provide services or providers of Hajj and Umrah pilgrimage services in Baitullah. Two different data presentations will provide us with valid information regarding a program and services offered to prospective pilgrims in need. From the analysis that will be done will minimize errors in the future.
\end{abstract}

Keywords: Analysis, Travel services, Hajj and Umrah, Prospective, Shariah Economy.

\section{A. Pendahuluan}

Ibadah Haji dan Umroh merupakan idaman setiap orang Islam untuk bisa melaksanakannya yang diperintahkan oleh agama. Haji menjadi bagian dari rukun iman yang kelima setelah syahadat, sholat, puasa, dan zakat. Haji dan umrah diwajibkan atas orang-orang yang kuasa (mampu), tiap orang laki-laki atau perempuan sekali seumur hidup. Oleh karena itu, Allah swt. mewajibkan bagi orang-orang yang sudah mampu dalam hal materi, fisik, maupun kesungguhan atau keikhlasan dalam menjalankannya. Sebagaimana firman Allah swt. dalam QS. alHajj ayat 27 yang artinya: 
"Yang artinya: Dan berserulah kepada manusia untuk mengerjakan haji, niscaya mereka akan datang kepadamu dengan berjalan kaki, dan mengendarai unta yang kurus yang datang dari segenap penjuru yang jauh." 1

Pengertian haji menurut bahasa ialah berniat kepada sesuatu yang dimuliakan. Pengertian haji secara istilah yaitu pekerjaan yang khusus yang dikerjakan pada waktu yang tertentu, dan tempat yang tertentu untuk tujuan yang tertentu. Dalam kitab "Figh al-Hajj" disebutkan pengertian haji secara bahasa yaitu al-qasd artinya berhajat atau berkehendak. Dan menurut syar' artinya berhajat mengunjungi Baitullah al-Haram untuk mengerjakan ibadah sebagai kewajiban terhadap perintah Allah. ${ }^{2}$ Sedangkan Umroh adalah berkunjung ke Ka'bah untuk melakukan serangkaian ibadah dengan syarat-syarat yang telah di tetapkan. Umrah disunahkan bagi muslim yang mampu yaitu pada tanggal 10 Dzulhijjah dan hari tasyrik yaitu tanggal 11,12,13 Dzulhijjah. ${ }^{3}$

Pada umumnya masyarakat muslim Indonesia melaksanakan haji dan umrah menuju Masjidil Haram di Makkah melalui travel haji dan umrah yang banyak tersebar di Indonesia. Banyaknya penawaran biro perjalanan haji dan umroh di Indonesia menimbulkan persaingan yang cukup ketat, hingga paket dan harga yang ditawarkanpun bervariasi. Masyarakat harus berhati-hati dan selektif serta kritis dalam memilih biro perjalanan sebab tidak sedikit yang melakukan tindak pidana penipuan pada sektor travel haji dan umrah.

Contohnya adalah kegagalan pemberangkatan jamaah pada 28 Maret 2017 lalu oleh biro perjalanan F Travel, dimana terdapat 72.682 jamaah yang gagal berangkat dengan total kerugian mencapai \pm 800 Milyar atau (Rp. 848.700.000.000). Pada saat kejadian itu jemaah diinapkan dihotel sekitar Bandara Soekarno Hatta. Hal itu pun membuat Kemenag melakukan klarifikasi, investigasi, advokasi, hingga mediasi dengan Jemaah. ${ }^{4}$ Kemudian sebuah penyelewengan dana umat dengan nilai yang fantastis sekitar $\pm 1,8$ Triliun rupiah dengan total jamaah lebih kurang 86.720 orang oleh biro perjalanan ABU Tour dengan beralamatkan pada Jl. Bay Raya No.32 i Kota Makasar dan terakhir penyelewengan dan yang dilakukan oleh dunia Tour yang terjadi pada PT. SBL yang beralamatkan di Gedung Wisma Bumi Putra Lt.6 Suite 602 Jl. Asia-Afrika No. 141-149 Bandung, sekitar 12.845 orang jamaah mengalami kerugian sekitar \pm 300 Miliyar.

Ibadah haji kemudian melibatkan banyak pihak atau stakeholder, misalnya agen perjalanan, koordinasi antarpemerintah, hubungan antarnegara, perusahaan katering, hotel, pembimbing haji, dan lain-lain. Walhasil, haji bukan saja menyangkut hal-hal yang bersifat religius, melainkan juga bersinggungan dengan persoalan lain termasuk bisnis dan ekonomi. ${ }^{5}$ Dengan begitu pemerintah merasa

1Departemen Agama RI, al-Qur'an dan Terjemahnya, (Jakarta: CV Diponegoro, 2005), h. 268.

2Muhammad Nuri, Pragmatisme Penyelenggaraan Ibadah Haji Di Indonesia, (Malaysia: University of Malay, 2014), h 145.

${ }^{3}$ Ajeng Tania, Analisis Program Pelayanan Jamaah Haji dan Umroh PT. Arminareka Perdana, (Jakarta: UIN Syarif Hidayatullah, 2014), h 29.

4https://www.cnnindonesia.com/nasional/2017 dikutip pada 2 Desember 2019

5Moeslim Abdurrahman, Haji, Turisme, dan Pencarian Kesalehan, (Jambi: IAIN Sultan Thaha Saifuddin, 2009, Jambi), h 159. 
penting untuk memberikan penjaminan hukum dalam penyelenggaraan ibadah haji dengan mengesahkan Undang-undang No 13 tahun 2008 tentang Penyelenggaraan Ibadah Haji. Undang-undang ini mengakomodir tentang hal memberikan pembinaan, pelayanan dan perlindungan yang sebaik-baiknya bagi jamaah haji dan umroh hingga mereka dapat menunaikan ibadah sesuai dengan ketentuan ajaran agama Islam.

Penyelenggaraan ibadah haji dan umroh diletakan atas prinsip prinsip dalam mengedepankan kepentingan jama'ah memberikan rasa keadilan dan kepastian efesiensi dan efektivitas, transparansi dan akuntabilitas, profesionalitas dan nirlaba. Prinsip-prinsip tersebut direfleksikan dalam sebuah kegiatan terkait dengan penyelenggaraan haji dan umroh, baik dalam bentuk pembinaan, pelayanan maupun perlindungan.

Namun sayangnya terjadi ketimpangan antara peningkatan calon jamaah haji dan upaya pelaksanaan operasional. Contohnya saja trend peningkatan jumlah kuota haji reguler Propinsi Lampung tidak sebanding dengan pelayanan yayasan Kelompok Bimbingan Ibadah Haji (KBIH). Menurut data dari kementrian agama Provinsi Lampung Setiap tahunnya jumlah Calon jamaah haji reguler yang mendaftarkan porsi haji terus meningkat yang berdampak pada daftar tunggu anterian menumpuk. Tahun 2018 saja daftar anterian sudah 15 tahun sedangkan tahun 2019 berjalan sudah mencapai 17 tahun data waiting list akibat jumlah pendaftaran Calon Jamaah Haji. Masih tingginya waiting list (daftar tunggu) bagi jamaah asal Indonesia, membuat Kementrian Agama (Kemenag) berencana mensosialisasikan kewajiban menunaikan ibadah haji sekali dalam seumur hidup. ${ }^{6}$

Agar biro perjalanan dapat memberikan kepuasan jamaah setidaknya hal-hal yang harus diperhatikan adalah memiliki karyawan yang profesional, tersedia sarana dan prasarana yang baik, tersedia semua produk yang diinginkan, bertanggung jawab kepada jamaah dari awal hingga selesai, mampu melayani secara cepat dan mampu memberikan kepercayaan kepada jamaah. ${ }^{7}$

Salah satu strategi bisnis adalah strategi differensiasi. Strategi differensiasi yaitu travel haji berusaha memasarkan jasa dengan karakteristik tertentu yang khas sehingga travel haji tersebut akan dianggap unik dan bahkan dianggap ekslusif oleh jamaah. ${ }^{8}$ Biro perjalanan haji dan umroh PT. Makkah Multazam Safir ataupun AlMadinah Tour \& Travel di Bandar Lampung yang bersama-sama merupakan badan usaha yang menyediakan pelayanan jasa atau penyedia jasa perjalanan ibadah haji dan umroh di baitullah. Meningkatkan mutu dan kualitas pelayanan ibadah haji dan umrah baik dari mulai sebelum keberangkatan sampai dengan kembali ke tanah air merupakan komitmen managemen di dalam menyediakan pelayanan dan mutu. Ini dapat dijelaskan dengan data pada kurun waktu tertentu yang mengacu pada persentase perubahan yang terjadi di bawah ini.

${ }^{6}$ Muhammad Yusuf Sayudi, Analisis Strategi Bauran Pemasaran Haji \& Umrah Pada Pt. Nratour \& Travel Jakarta Selatan, (Jakarta: UIN Jakarta, 2013), h. 1.

7Kasmir, Etika Customer Service, (Jakarta: PT. Raja Grafindo Persada, 2005), h. 9.

${ }^{8}$ Andi Chaermaya, Strategi Bisnis Haji PT. Arminareka Perdana (Studi Perekrutan Jamaah), (Makassar: UIN Alauddin, 2017), h. 5. 
Tabel 1

Daftar Perkembangan Jamaah Haji Khusus, Haji Plus-Plus, Umroh dan Umroh plus PT Makkah Multazam Safir tahun 2008-2018

\begin{tabular}{|c|c|c|c|c|c|c|c|c|}
\hline \multirow[b]{2}{*}{ No } & \multirow[b]{2}{*}{ Tahun } & \multicolumn{2}{|l|}{ Kuota } & \multirow{2}{*}{$\begin{array}{l}\text { Haji } \\
\text { Reguler }\end{array}$} & \multirow{2}{*}{$\begin{array}{l}\text { Haji } \\
\text { Khusus }\end{array}$} & \multirow{2}{*}{$\begin{array}{l}\text { Haji } \\
\text { Plus- } \\
\text { Plus }\end{array}$} & \multirow{2}{*}{$\begin{array}{l}\text { Umroh } \\
\text { Reguler }\end{array}$} & \multirow{2}{*}{$\begin{array}{l}\text { Umroh } \\
\text { Plus }\end{array}$} \\
\hline & & $\begin{array}{l}\text { Haji } \\
\text { Reguler }\end{array}$ & \begin{tabular}{|l} 
Haji \\
Khusus
\end{tabular} & & & & & \\
\hline 1 & 2008 & 193.000 & 17.000 & 45 & 11 & - & 120 & - \\
\hline 2 & 2009 & 193.000 & 17.000 & 135 & 20 & - & 130 & - \\
\hline 3 & 2010 & 194.000 & 17.000 & 158 & 24 & - & 134 & - \\
\hline 4 & 2011 & 194.000 & 17.000 & 150 & 24 & - & 136 & - \\
\hline 5 & 2012 & 204.000 & 17.000 & 162 & 21 & 4 & 127 & 8 \\
\hline 6 & 2013 & 163.200 & 13.600 & 95 & 22 & 7 & 230 & 15 \\
\hline 7 & 2014 & 163.200 & 13.600 & 90 & 14 & 8 & 238 & 13 \\
\hline 8 & 2015 & 163.200 & 13.600 & 86 & 15 & 9 & 240 & 16 \\
\hline 9 & 2016 & 163.200 & 13.600 & 45 & 17 & 14 & 235 & 24 \\
\hline 10 & 2017 & 194.000 & 17.000 & 45 & 17 & 16 & 168 & 25 \\
\hline 11 & 2018 & 194.000 & 17.000 & 45 & 18 & 12 & 170 & 27 \\
\hline
\end{tabular}

Sumber: Kementerian Agama Republik Indonesia

Kuota Haji Indonesia tahun 2019 ini berjumlah 221.000 jamaah, dengan rincian 194.000 haji reguler dan 17.000 haji khusus. Adapun data waiting list untuk haji khusus 8 tahun dengan jumlah pendaftaran sampai tahun 2019 berjalan 136.000 calon jamaah haji, demikian pula haji reguler yang telah mendaftarkan diri sampai dengan tahun 2019 berjalan dengan waiting list 16 tahun. Kondisi saat ini kapasitas Mesjidil Haram 1.000.000 orang dan pada waktu musim haji dapat menampung 4.000.000 orang.

Tabel 2

Biro Perjalanan Haji dan Umroh Al-Madinah Tour \& Travel

\begin{tabular}{|l|l|l|l|l|l|l|}
\hline \multirow{2}{*}{ No } & Tahun & Kuji Reguler & $\begin{array}{l}\text { Haji } \\
\text { Khusus }\end{array}$ & $\begin{array}{l}\text { Haji } \\
\text { Plus- } \\
\text { Plus }\end{array}$ & $\begin{array}{l}\text { Umroh } \\
\text { Reguler }\end{array}$ & $\begin{array}{l}\text { Umroh } \\
\text { Plus }\end{array}$ \\
\cline { 3 - 7 } & 2010 & 194.000 & 17.000 & - & - & - \\
\hline 2 & 2011 & 194.000 & 17.000 & - & 4 & 14 \\
\hline 3 & 2012 & 204.000 & 17.000 & - & 10 & 22 \\
\hline 4 & 2013 & 163.200 & 13.600 & - & 9 & 24 \\
\hline 5 & 2014 & 163.200 & 13.600 & 4 & 9 & 20 \\
\hline
\end{tabular}




\begin{tabular}{|l|l|l|l|l|l|l|}
\hline 6 & 2015 & 163.200 & 13.600 & 7 & 11 & 24 \\
\hline 7 & 2016 & 163.200 & 13.600 & 8 & 10 & 23 \\
\hline 8 & 2017 & 194.000 & 17.000 & 9 & 12 & 25 \\
\hline 9 & 2018 & 194.000 & 17.000 & 14 & 10 & 26 \\
\hline \multicolumn{2}{|l}{ Jumlah } & 42 & 75 & 178 \\
\hline
\end{tabular}

Sumber: Kementerian Agama RI \& Al-Madinah Tour \& Travel

Dua penyajian data yang berbeda akan memberikan kita informasi yang valid terkait sebuah program dan pelayanan yang ditawarkan kepada calon jamaah yang membutuhkan. Kemudian posisi data tersebut menyajikan sebuah titik perbedaan pelayanan dari masing-masing program. Perbedaan ini akan mempengaruhi secara signifikan akan pola dan cara pemasaran di dalam menarik minat calon jamaah untuk memilih dari masing-masing biro yang diminati.

Pengenalan biro perjalanan umrah dan haji sedikit jarang di iklankan di media sosial ataupun media komunikasi seperti televisi dan radio. Sehingga pengenalan melalui pengalaman mereka yang sudah melaksanakan ibadah umrah maupun haji kepada pembeli, tetangga, kerabat, dan anggota, keluarga yang sudah menggunakan biro perjalanan umrah dan haji. Dengan begitu terbentuk pemasaran secara Experiential Marketing. Tidak hanya itu, Experiential Marketing membuat konsumen membicarakannya secara terus menerus dan secara tidak langsung memasarkan produk yang dipakainya. Dengan cara ini konsumen menjadi tidak ragu untuk memilih layanan tersebut sehingga timbul kepercayaan yang menjadikan loyalitas terhadap perusahaan layanan yang sebelumnya mereka gunakan dan loyalitas pelanggan tersebut bisa membuat sisi positif bagi perusahaan. Dengan kata lain, konsumen menyebarkan informasi kepada calon pelanggan secara word of mouth. ${ }^{9}$

Penerapan strategi pemasaran menjadi kunci penting keberhasilan sebuah perusahaan dalam meraih daya saing. Keberhasilan suatu organisasi dalam memenangkan persaingan ditentukan oleh strategi. Strategi adalah upaya yang dimiliki individu dan unsur-unsur yang ada dalam organisasi untuk memiliki keterampilan dan memanfaatkan sumber daya sesuai dengan kondisi lingkungan kerja. ${ }^{10}$

Kotler menyatakan bahwa strategi pemasaran merupakan solusi untuk menangani aktivitas yang berkaitan dengan produk dan jasa. ${ }^{11}$ Strategi pemasaran dilakukan oleh pihak PT. Makkah Multazam Safir maupun Al-Madinah tour \& travel merupakan solusi untuk mengatasi permasalahan dalam meraih daya saing pada pemasaran paket haji dan umrah.

${ }^{9}$ Nadiah Yustifa dan Edy Yulianto, Pengaruh Experiential Marketing Dan Word Of Mouth Terhadap Loyalitas Pelanggan (Survei pada konsumen PT Alhamdi Global Wisata periode umrah 2015 sampai dengan Juni 2017), Malang: Jurnal Administrasi Bisnis (JAB) | Vol. 57 No. 1 April 201, h. 47-48.

${ }^{10}$ Chandler, S. Peter, 2009, Managing Problems Loans, (Seattle, Richard D. Irwin Inc),h. 39.

11Philip Kotler, 2008, Manajemen Pemasaran, Edisi 1 dan 2, (Jakarta: Prenhallindo), h. 24. 


\section{B. Rumusan Masalah}

Berdasarkan latar belakang tersebut, maka permasalahan yang diangkat dalam penelitian ini dapat dirumuskan sebagai berikut:

1. Bagaimana strategi pemasarannya meningkatkan kualitas daya saing dan pelayanan biro perjalanan haji dan umroh pada PT. Makkah Multazam Safir dan Al-Madinah?

2. Bagaimana kualitas pelayanan yang diberikan sebagai upaya peningkatan kualitas daya saing biro perjalanan haji dan umroh pada PT. Makkah Multazam Safir dan Al-Madinah dan kendala yang dihadapi?

\section{Metode Penulisan}

Penelitian ini merupakan penelitian yang bersifat kualitatif, yaitu suatu pendekatan penelitian yang menghasilkan data deskriptif berupa data-data tertulis/lisan dari orang-orang dan perilaku yang dapat diamati ${ }^{12}$. Pendekatan kualitatif menekankan pada makna dan pemahaman dari dalam (verstehen), penalaran, definisi suatu situasi tertentu (dalam konteks tertentu), lebih banyak meneliti hal-hal yang berhubungan dengan kehidupan sehari-hari. Pendekatan kualitatif lebih mementingkan pada proses dibandingkan dengan hasil akhir; oleh karena itu urut-urutan kegiatan dapat berubah-ubah tergantung pada kondisi dan banyaknya gejala-gejala yang ditemukan ${ }^{13}$.

Adapun bentuk penelitiannya adalah penelitian kualitatif deskriptif, yaitu penelitian yang menggambarkan suatu objek yang berkenaan dengan masalah yang diteliti tanpa mempersoalkan hubungan antar variabel penelitian ${ }^{14}$. Dalam penelitian ini penulis memilih subjek penelitian di PT. Makkah Multazam Safir Way Halim Permai Bandar Lampung dan Al-Madinah Tour \& Travel Sukarame. Subjek penelitian ini adalah pemilik perusahaan, komisaris PT, bagian humas, bagian administrasi, dan jamaah PT. Makkah Multazam Safir serta jamaah Al-Madinah Tour \& Travel.

Jenis data yang digunakan dalam penelitian ini yaitu jenis data kualitatif. Karena data yang diperoleh tersebut dapat diukur secara tidak langsung artinya tidak menggunakan angka melainkan menggunakan kata-kata atau kalimat. ${ }^{15}$ Dalam penelitian ini, penulis mengadakan wawancara (interview) secara langsung maupun tidak langsung kepada pihak-pihak untuk memperoleh data yang lengkap dan akurat. Disamping itu penulis juga mengadakan observasi yang terdiri dari pengamatan dan mencatat secara langsung terhadap objek penelitian yaitu mengamati pelaksanaan program pelayanan jamaah haji dan umroh secara langsung dan mengamati rekaman perjalanan haji dan umroh PT. Makkah Multazam Safir dan Al-Madinah Tour \& Travel.

${ }^{12}$ Lekxy J Moleong , Metodologi Peneltian Kualitatif, Bandung: Remaja Rosdakarya, 2003, hal. 4.

${ }^{13}$ Mohammad Mulyadi, Penelitian Kuantitatif Dan Kualitatif Serta Pemikiran Dasar Menggabungkannya, Jurnal Studi Komunikasi Dan Media, Jakarta: Kementrian Komunikasi dan Informatika, 2011, hal. 134

14Sanapiah Faisol, Format-format Penelitian Sosial, Jilid 1, Jakarta: Rajawali Press, 1992, hal. 18.

${ }^{15 S}$ Sutrisno Hadi, Metodologi Research, Jilid I, Yogyakarta : Andi Offset, 1995, hal. 66. 
Data dalam penelitian ini pada hakekatnya berupa kata-kata, kalimat, paragraf-paragraf atau angka dan dinyatakan dalam bentuk narasi yang bersifat deskripitif mengenai peristiwa-peristiwa nyata yang tejadi di PT. Makkah Multazam Safir dan Al-Madinah Tour \& Travel. Berdasarkan wujud dan sifat data tersebut maka teknik analisa data yang digunakan dalam penelitian ini adalah analisa data kualitatif deskriptif. ${ }^{16}$ Dalam penerapan teknik analisa data kualitatif deskriprif menggunakan langkah-langkah seperti reduksi data, display data, serta penyimpulan.

\section{Pembahasan}

Menurut Mathew dan Huberman Pemasaran merupakan sebuah peristilahan, berasal dari kata "pasar" yang artinya tempat terjadinya pertemuan transaksi jualbeli atau tempat bertemunya penjual dan pembeli. Kondisi dinamika masyarakat dan desakan ekonomi, dikenal istilah "pemasaran" yang berarti melakukan suatu aktivitas penjualan dan pembelian suatu jasa, didasari oleh kepentingan atau keinginan untuk membeli dan menjual . Agama Islam sendiri memiliki ilmu yang lengkap mengenai prosedur, landasan dan aturan main dalam praktik pemasaran. Oleh karena itu pemasaran yang berlandaskan ajaran Islam adalah praktik pemasaran berdasarkan etika. Kepatuhan terhadap etika akan mengangkat standar prilaku pemasaran dan konsumen secara seimbang dan saling menguntungkan sehingga tercipta kerangka nilai yang bermanfaat bagi perusahaan, mampu membangun harmoni dan kerjasama antara pemasar dan target pasar. ${ }^{17}$

Ketika kita bicara pemasaran maka yang sangat penting untuk diingat adalah Strategi Pemasaran. Strategi pemasaran mempunyai kaitan yang erat dengan kegiatan saluran distribusi, di mana saluran distribusi merupakan bagian dari strategi pemasaran yang diterapkan oleh perusahaan dalam meningkatkan peningkatan penjualan suatu produk ${ }^{18}$. Strategi pemasaran dapat dilihat dari 3 (tiga) strategi yang biasa dikenal dengan istilah strategi STP (Segmentation, Targeting, Positioning). Bahwa dalam melakukan suatu pemasaran produk, selalu memerhatikan pentingnya daya saing (segmentation) yang dapat memenuhi target penjualan produk (targeting) tanpa mengabaikan tata letak dari suatu kegiatan pemasaran atau positioning. Ketiga strategi pemasaran ini menentukan berhasil tidaknya suatu kegiatan pemasaran. ${ }^{19}$

Teori orientasi pelanggan menyatakan keberhasilan aktivitas pemasaran bila perusahaan mampu mempertahankan dan mensinambungkan keberadaan pelanggan dalam mewujudkan tujuan perusahaan ${ }^{20}$. Sedangkan teori market competition dari Kotler menyatakan bahwa kegiatan pemasaran merupakan kegiatan yang menghimpun berbagai orientasi sesuai dengan jumlah pelanggan, pihak yang berkompetisi dan koordinasi fungsional dalam memengaruhi peningkatan kinerja

16Mathew and Huberman, Analisis Data Kualitatif, (Jakarta: Universitas Indonesia, 1992), h. 15-16.

${ }^{17}$ Nur Asnawi, Pemasaran Syariah Teori, Filosofi dan Isu-Isu Kontemporer, (Jakarta: Rajawali Pers,) h. vi-vii.

18Gasperz, Marketing, Third Edition, (USA: Richard D. Irwin,. 2008), h. 74.

19 Philip Kotler , 2008, Manajemen Pemasaran..., h. 58.

20 Samuelson, Marketing orientation, (Prentice Hall Cliffs: New Jersey, 2003), h. 22. 
pemasaran. Artinya orientasi memainkan peranan penting untuk menciptakan berbagai peluang pasar potensial, kompetitif dan terdesain. ${ }^{21}$

Mengembangkan daya saing dengan memahami orientasi pelanggan minimal mempertahankan empat aspek dari pelanggan yaitu tuntutan kebutuhan (need), keinginan (desire), harapan (expectation) dan loyalitas (loyalty) pelanggan. Makin terpenuhi empat aspek yang menjadi dasar orientasi pelanggan, maka semakin mudah perusahaan untuk mengembangkan daya saing. Steband menyatakan bahwa mengenal daya saing, berarti mengenal kebutuhan, keinginan, harapan dan loyalitas pelanggan untuk dipelihara dan dijaga oleh pihak perusahaan ${ }^{22}$. Kepuasan dalam kasus perjalanan Haji dan Umrah agen ketika pelanggan mengukur dan menilai harapan mereka dan kinerja aktual semua jenis layanan yang disediakan oleh agen perjalanan Haji dan Umrah, termasuk hotel, katering, keramahtamahan karyawan, dll. Nilai-nilai tersebut diperoleh setelah konsumen menggunakan layanan dari agensi perjalanan Haji dan Umrah. ${ }^{23}$

Kaitan aktivitas daya saing dengan orientasi perusahaan, tidak dapat dipisahkan dari aktivitas persaingan. Teori pesaing atau competitor orientation theory merupakan salah satu teori yang dilakukan untuk memecahkan berbagai problematika perilaku dan tindakan marketer dalam melakukan persaingan. Teori competitor orientation dari Trinkler menyatakan bahwa setiap persaingan mengutamakan persaingan yang kompetitif (competitive advantage) dan persaingan yang menguntungkan (competitive comparative). Kedua wujud persaingan ini diperlukan dalam kegiatan pemasaran untuk mewujudkan tujuan daya saing. ${ }^{24}$

Turut serta dalam kompetisi pasar pada bidang perjalanan umrah dan haji setidaknya para biro perjalanan harus terlebih dahulu memenuhi persyaratan standar, sesuai dengan Kementrian Agama RI untuk menjadi agen perjalanan haji dan umrah, syarat dan ketentuan menggambarkan sebagai berikut: 1) Memiliki lisensi sebagai agen perjalanan. 2) Telah beroperasi dengan minimal 2 tahun sebagai agen perjalanan. 3) Memiliki kemampuan teknis untuk melakukan ziarah yang mencakup kemampuan sumber daya manusia, manajemen, dan fasilitas. 4) Memiliki kemampuan finansial untuk mengatur ziarah sebagai bukti dengan jaminan bank. 5) Memiliki lembaga penyelenggara haji mitra di Arab Saudi yang memiliki izin resmi dari Pemerintah Arab Saudi. 6) Memiliki komitmen untuk mengatur haji dan umrah sesuai dengan standar yang ditetapkan oleh Menteri. ${ }^{25}$

Berdasarkan berbagai teori yang telah disebutkan juga syarat untuk menjadi agen perjalanan dalam hal umroh dan haji maka penulis memilih 2 agen perjalanan. Yang pertama adalah PT. Makkah Multazam Safir didirikan tahun 2008 notaris Ayi Ruhiyat, SH dengan akte No. 13 pada tanggal 14 November 2008, merupakan

21Philip Kotler, 2008, Manajemen Pemasaran..., h. 68.

22Golt Steband JR, Marketing performance Management in Organization, Revision Edition, (Boston: Mas Hougton Mifflin Company, 2008), h. 12.

${ }^{23}$ Kiki Oktora dan Adrian Achyar, The Effect of PostPurchased Perceived-Value towards the Relationship Quality of Hajj and Umrah Travel Agencies in Indonesia, (The South East Asian Journal Of Management, 2014), h, 32.

24Trinkler, Marketing and Strategy in Marketing, (Canada: McMIllan, 2008), h. 54.

${ }^{25}$ Agita Puspa Dias, Manajemen Risiko Pada Industri Layanan Jasa Di Pt. Rama Mustika Agen Travel Haji Dan Umrah, (Bandung: Institut Teknologi Bandung, 2017), h. 15. 
perusahaan yang bergerak di Pelayanan Ibadah Umroh dan Haji beralamat kantornya di Jl. Arif Rahman Hakim No. 5 Kelurahan Way Halim Permai, Kecamatan Way Halim - Kota Bandar Lampung Provinsi Lampung. Dan yang kedua adalah Perusahaan Al-Madinah Tour \& Travel yang didirikan dengan akte notaris 21 Oktober 2010 dengan No. 06 Notaris Edyawaty, SH yang berkonsentrasi bergerak dalam bidang pelayanan, seperti; 1) Umroh dan Haji, 2) Ticketing, 3) Jasa Cargo dan 4) Transportasi.

Dan yang kedua adalah Perusahaan Al-Madinah Tour \& Travel yang didirikan dengan akte notaris 21 Oktober 2010 dengan No. 06 Notaris Edyawaty, SH yang berkonsentrasi bergerak dalam bidang pelayanan, seperti; 1) Umroh dan Haji, 2) Ticketing, 3) Jasa Cargo dan 4) Transportasi. Perusahaan ini yang didirikan dan dipimpin langsung oleh H.A. Chalik Nasution. Latar belakang riwayat beliau dahulu adalah Pimpinan Pembangunan Perusahaan cabang Medan. Berkontribusi di dalam kepersertaan dan pengurus aktif dalam sebuah Asosiasi Pemancing Seluruh Indonesia yang ada di Miami (USA). Mengabdikan diri di dalam pelayanan haji dan umroh sebagai pelaksana tugas beberapa perusahaan perjalanan haji dan umroh dan yayasan bimbingan haji dan umroh.

PT. Makkah Multazam Safir dan Al-Madinah Tour \& Travel dalam strategi pemasarannya menyuguhkan beberapa pilihan seperti haji khusus, haji plus, umrah plus dan beberapa lainnya. Pada program haji Khusus, dengan banyaknya animo masyarakat untuk berangkat haji dengan cepat program haji khusus ternyata pendaftaran sampai tahun 2019 sudah mencapai 136.000 an jamaah sehingga jumlah anterian jamaah waiting listnya 8 tahun. Hal ini disebabkan jumlah Kuota haji khusus tetap 17.000 orang sedangkan adanya tambahan kuota dari Kerajaan Saudi dimasukan, ditambahkan dalam kuota haji reguler , kebijakan Kementerian Agama dilaksanakan untuk mengurangi ,menumpuknya yang sudah mendaftarkan haji reguler tahun 2019 berjalan sudah mencapai 111.029 dengan daftar anterian 16 tahun (waitinglist). Dalam penyelenggaran haji khusus beberapa perusahaan perjalanan selalu berusaha mengkoodinasikan penyelenggaraan, pelayanan, informasi untuk membentuk Asosiasi yang membawahi Tour \& Travel Penyelenggara Ibadah Haji Khusus (PIHK).

Pada haji plus biasanya dilakukan PIHK yang jumlah jamaah haji khusus yang mendaftarkan kurang banyak sehingga mengharapkan ada tambahan dari jamaah Haji Plus-Plus (non-kuota), dengan menggunakan fasilitas visa furoda, visa ziarah dari otoritas kerajaan Saudi Arabia langsung diluar wewenang dari pada pemerintah Indonesia. Adapun fasilitas penerbangan, akomodasi hotel, bus transfortasi, tenda haji armina yang didapatkan sama dengan Haji Khusus Pemerintah (kuota) bahkan bisa lebih baik . Pada umumnya yang menggunakan paket Haji Plus-Plus orang yang telah lanjut usia, orang yang memiliki kecukupan dana untuk melakukan Ibadah Haji langsung tanpa Waiting List 8 tahun saat ini.

Umroh Reguler, pemberangkatan ke tanah suci untuk melakukan ibadah umroh reguler : Jeddah - Makkah - Madinah dengan rute penerbangan TKG-CGKJED/MED-Pp. Adapun teknis pelaksanaan dengan menggunakan dokumen visa Umroh dan dipandu oleh mutowwif dengan akomodasi/ fasilitas yang sudah disiapkan. Hal ini dapat dilakukan sepanjang masa tanpa kuota diluar bulan Haji. 
Umroh Plus, untuk menambah, melayani tamu-tamu Allah setelah melakukan ibadah umroh jamah berkehendak ziarah ke tempat napak tilas Nabi di Jazirah Arab seperti Umroh Plus : Turkey, Cairo, Dubai dan Aqsho, yang dikemas biro perjalanan dalam bentuk paket Umroh Plus.

Tour Muslim perjalanan yang dilakukan jamaah tanpa umroh, biasanya dilakukan bagi jamaah yang telah melaksanakan Haji, Umroh, Umroh Plus ataupun Jamaah yang ingin berkunjung ke Negara Islam lainnya, seperti Turkey, Cairo, Dubai, Aqsho dan lain lain. Bahkan ada yang ingin berkunjung ke negara lainnya menikmati kebesaran Alah seperti Jepang, Korea, India, Dubai dan Beijing. Program ini sifatnya masih tentative, bila ada permintaan jamaah baru kita lakukan.

Perbedaan haji plus dengan haji reguler biasanya terletak di cara pendaftaran, besarnya biaya yang dibayarkan, serta fasilitas dan pelayanan yang didapat. Karena biaya yang dibayarkan lebih banyak (biasanya sampai dua kali lipat lebih besar daripada haji reguler). Meski sama-sama bisa masuk dalam daftar tunggu, waktu tunggu calon jemaah haji plus lebih singkat dibandingkan jemaah haji reguler.. Perbedaan haji plus dengan haji regular juga bisa dilihat dari tempat menginap para jamaah. ${ }^{26}$

Strategi pemasaran mempunyai kaitan yang erat dengan kegiatan saluran distribusi, di mana saluran distribusi merupakan bagian dari strategi pemasaran yang diterapkan oleh perusahaan dalam meningkatkan peningkatan penjualan suatu produk ${ }^{27}$. Strategi pemasaran dapat dilihat dari 3 (tiga) strategi yang biasa dikenal dengan istilah strategi STP (Segmentation, Targeting, Positioning). Bahwa dalam melakukan suatu pemasaran produk, selalu memerhatikan pentingnya daya saing (segmentation) yang dapat memenuhi target penjualan produk (targeting) tanpa mengabaikan tata letak dari suatu kegiatan pemasaran atau positioning. Ketiga strategi pemasaran ini menentukan berhasil tidaknya suatu kegiatan pemasaran.28

Setiap biro perjalanan, agar dapat menimbulkan trust pada pembeli maka penting untuk mengadakan pencantuman hak dan kewajiban bagi calon jamaah Haji Plus dalam suatu perjanjian tertulis dapat digunakan sebagai pedoman yang bersifat mengikat bagi para pihak dalam pelaksanaan penyelenggaraan ibadah Haji Plus untuk calon jamaah maupun pihak biro itu sendiri, karena perjanjian yang paling banyak dilakukan oleh para pihak yaitu dengan bahasa yang sempurna secara lisan dan tertulis, tujuan perjanjian secara tertulis adalah agar memberikan kepastian hukum bagi para pihak dan sebagai alat bukti yang sempurna dan otentik di kala timbul adanya sengketa yang dialami di kemudian hari. ${ }^{29}$ Persaingan KBIH di yang sangat ketat membuat banyak KBIH mati suri atau bahkan tidak beroperasi

26http:/ / labbaik.id/perbedaan-haji-plus-dengan-haji-reguler-untuk-jemaah-haji di kutip pada 1 Desember 2019.

27Gasperz, 2008. Marketing. Third Edition, (USA: Richard D. Irwin), h. 74.

28Philip Kotler , 2008, Manajemen Pemasaran..., h. 58.

${ }^{29}$ Anggita Ning Tyas Sari, Pertanggung Jawaban Hukum Terhadap Pelaksanaan Perjanjian Pemberangkatan Ibadah Haji Antara Biro Penyelenggara Ibadah Haji Khusus Dengan Calon Jamaah Haji Plus (Studi Kasus di PT. Nur Ramadhan Wisata Cabang Yogyakarta), (Surakarta: Universitas Muhammadiuyah Surakarta, 2015), h. 7 
lagi. Namun tidak dengan PT. Makkah Multazam Safir, dimana hal ini dapat dijelaskan pada tabel perkembangan jamaah sebagai berikut:

\section{Tabel 4}

Perkembangan Jamaah Haji Khusus dan Umrah

PT. Makkah Multazam Safir tahun 2008-2018

\begin{tabular}{|c|c|c|c|c|c|c|c|c|}
\hline \multirow[b]{2}{*}{ No } & \multirow[b]{2}{*}{ Tahun } & \multicolumn{2}{|l|}{ Kuota } & \multirow{2}{*}{$\begin{array}{l}\text { Haji } \\
\text { Reguler }\end{array}$} & \multirow{2}{*}{$\begin{array}{l}\text { Haji } \\
\text { Khusus }\end{array}$} & \multirow{2}{*}{$\begin{array}{l}\text { Haji } \\
\text { Plus- } \\
\text { Plus }\end{array}$} & \multirow{2}{*}{$\begin{array}{l}\text { Umroh } \\
\text { Reguler }\end{array}$} & \multirow{2}{*}{$\begin{array}{l}\text { Umroh } \\
\text { Plus }\end{array}$} \\
\hline & & $\begin{array}{l}\text { Haji } \\
\text { Reguler }\end{array}$ & $\begin{array}{c}\text { Haji } \\
\text { Khusus }\end{array}$ & & & & & \\
\hline 1 & 2008 & 193.000 & 17.000 & 45 & 11 & - & 120 & - \\
\hline 2 & 2009 & 193.000 & 17.000 & 135 & 20 & - & 130 & - \\
\hline 3 & 2010 & 194.000 & 17.000 & 158 & 24 & - & 134 & - \\
\hline 4 & 2011 & 194.000 & 17.000 & 150 & 24 & - & 136 & - \\
\hline 5 & 2012 & 204.000 & 17.000 & 162 & 21 & 4 & \begin{tabular}{|l|}
137 \\
\end{tabular} & 8 \\
\hline 6 & 2013 & 163.200 & 13.600 & 95 & 22 & 7 & 230 & 15 \\
\hline 7 & 2014 & 163.200 & 13.600 & 90 & 14 & 8 & 238 & 13 \\
\hline 8 & 2015 & 163.200 & 13.600 & 86 & 15 & 9 & 240 & 16 \\
\hline 9 & 2016 & 163.200 & 13.600 & 45 & 17 & 14 & 235 & 24 \\
\hline 10 & 2017 & 194.000 & 17.000 & 45 & 17 & 16 & 168 & 25 \\
\hline 11 & 2018 & 194.000 & 17.000 & 45 & 18 & 12 & 170 & 27 \\
\hline \multicolumn{4}{|c|}{ Jumlah } & 1056 & 282 & 70 & 1.275 & 128 \\
\hline
\end{tabular}

Sumber: Kementerian Agama Republik Indonesia

Perkembangan, peningkatan jumlah jemaah tersebut, dapat membuktikan kualitas dan pelayanan di PT. Makkah Multazam Safir sangat memuaskan. Selain itu, tingkat kepuasan konsumen dan kepercayaan mitra kerja juga terus meningkat jumlah jamaah, sarana prasarana, serta pelayanan dapat terus ditingkatkan. PT. Makkah Multazam Safir menyediakan keleluasaan kepada calon jamaahnya untuk memilih bulan keberangkatan Umrah-nya, jadwal menunggu 6 bulan hingga menunggu 1 bulan hingga keberangkatan.

Berikut adalah perbandingan produk yang ditawarkan oleh PT. Makkah Multazam Safir dan Al-Madinah Tour \& Travel:

\begin{tabular}{|l|l|l|l|l|}
\hline \multirow{2}{*}{ Paket } & Variasi & \multirow{2}{*}{ Durasi } & \multicolumn{2}{|l|}{ Harga Paket } \\
\cline { 4 - 5 } & & & Multazam & Al-Madinah \\
\hline \multirow{2}{*}{$\begin{array}{l}\text { Haji Reguler } \\
\text { Pemerintah }\end{array}$} & - & 41 Hari & Rp. 34.500.000,- & - \\
\hline \multirow{3}{*}{ Haji Khusus } & & & & \\
\cline { 3 - 5 } & Quard & 26 Hari & Rp. 145.000.000,- & Rp. 159.500.000,- \\
\cline { 2 - 5 } & Double & 26 Hari & Rp. 159.500.000,- & Rp. 174.000.000,- \\
\hline Haji Plus Plus & Quard & 26 Hari & Rp. 174.000.000,- & Rp. 188.500.000,- \\
\hline
\end{tabular}




\begin{tabular}{|c|c|c|c|c|}
\hline & Triple & 30 Hari & Rp. 235.000.000,- & Rp. 250.000.000,- \\
\hline & Double & 30 Hari & Rp. 250.000.000,- & Rp. $260.000 .000,-$ \\
\hline \multirow{3}{*}{ Umrah Reguler } & Quard & 9 Hari & Rp. $26.000 .000,-$ & Rp. 27.000.000,- \\
\hline & Triple & 9 Hari & Rp. 27.500.000,- & Rp. 28.000.000,- \\
\hline & Double & 9 Hari & Rp. $30.000 .000,-$ & Rp. 29.000.000,- \\
\hline \multirow{3}{*}{$\begin{array}{l}\text { Umrah } \\
\text { Dubai }\end{array}$} & Quard & 9 Hari & Rp. 25.500.000,- & Rp. 27.000.000,- \\
\hline & Triple & 9 Hari & Rp. $26.500 .000,-$ & Rp. 28. \\
\hline & Double & 9 Hari & Rp. 28.500.000,- & Rp. 29.0 \\
\hline \multirow{3}{*}{$\begin{array}{l}\text { Umrah } \\
\text { Turkey }\end{array}$} & Quard & 12 Hari & Rp. 35.500.000,- & Rp. $37.000 .000,-$ \\
\hline & Triple & 12 Hari & Rp. 37.500.000,- & Rp. 39.000.000,- \\
\hline & Double & 12 Hari & Rp. 39.50 & Rp. 41.0 \\
\hline \multirow{3}{*}{$\begin{array}{l}\text { Umroh } \\
\text { Cairo }\end{array}$} & Quard & 12 Hari & Rp. 39.00 & Rp. 37.5 \\
\hline & Triple & 12 Hari & Rp. 40.0 & Rp. 38. \\
\hline & Double & 12 Hari & Rp. 43.000. & Rp. 40.0 \\
\hline \multirow{3}{*}{$\begin{array}{l}\text { Umrah Plus } \\
\text { Al Aqso }\end{array}$} & Quard & 13 Hari & Rp. 49.500.000,- & Rp. 47.850.000,- \\
\hline & Triple & 13 Hari & Rp. 50.750.000,- & Rp. 49.500.000,- \\
\hline & Double & 13 Hari & Rp. 52.925.000,- & Rp. 50.750.000,- \\
\hline
\end{tabular}

Dengan menampilkan 2 perusahaan Penyelenggara Haji dan Umroh yang penulis dapat membandingkan performance strategi pelayanan dan strategi pemasaran produk dilengkapi obyektivitas terhadap data-data yang disajikan dari biro lainya terkait dengan strategi pelayanan dan strategi marketing mengharapkan jamaah memilih salah satunya. Sebagai bentuk komitmen yang dijalankan oleh masing-masing badan usaha jasa tersebut maka secara terfokus memberikan sebuah pelayanan yang sangat mempermudah dan menekan angka margin eror. Hal tersebut memberikan penilaian tersendiri terhadap kinerja sebuah managemen yang dinilai sudah berkompeten di dalam bidang pelayanan jasa khususnya haji dan umroh.

Dari variasi paket diatas yang membedakan adalah dari segi hotel, pesawat dan lama perjalanan sehingga perbedaan itu berpengaruh pada harga. PT. Makkah Multazam Safir mengemas paket sedemikian rupa bahwa produk yang mereka jual adalah produk sesuai kebutuhan konsumen. Untuk akomodasi penerbangan PT. Makkah Multazam Safir lebih banyak menyediakan produk penerbangan Garuda, sebagain besar dalam memberangkatkan jamaahnya menggunakan Garuda. Banyak jamaah yang menganggap Garuda lebih menjamin keamanan dan pelayanannya yang continue dengan trayek penerbangan yang tepat waktu (Connecting) TKG-CGKJED/MED. Dalam pemesanan seat penerbangan, PT. Makkah Multazam Safir tidak membedakan antara kelas bisnis dan ekonomi. penjualannya diserahkan kepada jamaah untuk memilih paket bisnis atau ekonomi.

Demikian pula yang dilakukan oleh perusahaan Al-Madinah Tour \& Travel adalah dalam melakukan pelayanan dengan menyajikan paket yang terkonsentrasi pada paket umroh reguler, umroh plus, tour muslim dan haji plus dan Haji plusplus. Inilah yang selanjutnya akan menimbulkan sebuah aspek persaingan agak berkurang, dikarenakan sebuah penyajian harga yang ditawarkan berimbang dan 
dilakukan pelayanan yang prima.

Muslim yang ingin melakukan haji dan umrah akan memilih agen perjalanan haji dan umrah yang menyediakan layanan ini dengan harapan bahwa mereka dapat memberikan bantuan yang memuaskan dan mendukung selama ritual haji dan umrah. Dalam banyak kasus, pelanggan tidak akan ragu untuk membayar lebih untuk mendapatkan kepuasan dan layanan premium tersebut. Untuk konsumen jenis ini, uang bukanlah opsi yang penting dan mereka tidak lebih suka harga murah. Dengan demikian, perusahaan yang memberikan nilai yang berarti atau manfaat nyata bagi konsumen akan mendapatkan lebih banyak keuntungan dibandingkan dengan pesaing mereka. ${ }^{30}$

Persaingan dalam artian persaingan yang positif pada dasarnya direkomendasikan dalam Islam, termasuk persaingan dalam mendapatkan kekayaan saat menjalankan bisnis. Bahkan di Al-Qur'an pun sudah dijelaskan dalam QS al-Baqarah ayat 148 yang artinya:

"Dan bagi tiap-tiap umat ada kiblatnya (sendiri) yang ia menghadap kepadanya. Maka berlomba-lombalah (dalam membuat) kebaikan. Di mana saja kamu berada pasti Allah akan mengumpulkan kamu sekalian (pada hari kiamat). Sesungguhnya Allah Maha Kuasa atas segala sesuatu." 31

Melihat keadaan bahwa ada beberapa pelanggan yang berkeinginan menunaikan ibadah haji dan umrah tetapi tabungan mereka belum cukup, PT. Makkah Multazam Safir memberi solusi dengan berkerjasama dengan pihak Bank BNI Syariah, Bank Mandiri Syari'ah dan BRI Syariah. Prosedurnya jamaah yang mengurus ke Bank tersebut untuk mendapatkan talangan, kemudian menyetorkannya ke PT. Makkah Multazam Safir. Hal ini semacam penambahan fitur kenyamanan saja bagi jamaah yang membutuhkan.

Berdasar Pasal 1 ayat 4 Peraturan Menteri Agama Nomor 30 Tahun 2013 tentang Bank Penerima Setoran Biaya Penyelenggaraan Ibadah Haji, bahwa Dana Talangan Haji adalah dana yang diberikan sebagai bantuan sementara tanpa mengenakan imbalan oleh Bank Penerima Setoran (BPS) BPIH kepada calon jamaah haji.Produk dana talangan haji merupakan solusi bagi sebagian muslim yang tidak dapat mencukupi biaya haji secara tunai dengan berdasar prinsip Qard wal Ijarah, yaitu akad pemberian pinjaman dari bank untuk nasabah yang disertai dengan penyerahan tugas agar bank menjaga barang jaminan yang diserahkannya, dalam arti kata, pihak bank menjaga jaminan yang diberikan oleh nasabahnya. ${ }^{32}$

Dari pemaparan diatas, penulis menganalisa bahwa strategi PT. Makkah Multazam Safir dalam menetapkan produknya sebenamya tidak jauh berbeda dengan perusahaan lainnya yang bergerak pelayanan haji dan umrah. Strategi Pilihan produk kepada pelanggan dari perbedaan variasi dalam pembelian tiket

\footnotetext{
${ }^{30}$ Dina Fitrisia Septarini, The correlation of the value of amanah and islamic pricing theory with customer satisfaction and its implication on customer loyalty in hajj and umrah service products in surabaya, Journal of Islamic Financial Studies, 2017, h 47-48.

${ }^{31}$ QS. Al-Baqarah ayat 148

32Della Edwinar, Status Hukum Dana Talangan Haji Bagi Calon Jamaah Haji, (Malang: Universitas Brawijaya, 2015), h. 3.
} 
pesawat dan hotel sesuai dengan keinginan konsumen. Selain itu, guna mempertahankan mutu produk dengan memberikan jadwal pemberangkatan yang tepat dan terjadwal 2 kali sebulan.

Jika kita kembali pada teori pemasaran, pembeli di masing- masing segmen diasumsikan cukup serupa dalam hal keinginan dan kebutuhan, walaupun tidak ada dua pembeli yang benar-benar serupa. Pemasaran segmen menawarkan beberapa manfaat dibandingkan pemasaran massal. Perusahaan dapat menciptakan penawaran produk atau jasa yang lebih selaras dengan mengenakan harga yang pantas bagi kelompok sasaran tertentu. Pemilihan saluran distribusi dan saluran komunikasi menjadi jauh lebih mudah.

Pola segmentasi pasar diidentifikasi berupa segmen preferensi terdiri dari preferensi homogen, preferensi tersebar dan preferensi terkelompok. Prosedur segmentasi pasar mencakup survei, analisis dan pembentukan profil. Jika kita melihat segmentasi pasar yang terjadi adalah dalam hal pelayanan.

Menurut Schnaars tujuan suatu bisnis adalah untuk menciptakan para pelanggan merasa puas. Kualitas jasa yang unggul dan konsisten dapat menumbuhkan kepuasan pelanggan dan akan memberikan berbagai manfaat. Kepuasan pelanggan dipengaruhi oleh persepsi kualitas jasa, kualitas produk, harga dan faktorfaktor yang bersifat pribadi serta yang bersifat situasi sesaat. Salah satu faktor yang menentukan kepuasan pelanggan adalah persepsi pelanggan mengenai kualitas jasa yang berfokus pada lima dimensi kualitas jasa yang diunkapkan Parasuraman dalam Kotler yaitu kualitas jasa meliputi keandalan (reliability), daya tanggap (responsiveness), jaminan (assurance), empati (empathy), dan bukti langsung (tangible), yaitu: bukti fisik (tangibles), keandalan (reliability), daya tanggap (responsiveness), jaminan (assurance) , empati (empathy). ${ }^{33}$

Yang dimaksud dengan Analisis Reliability (Reliabilitas) adalah analisis yang meliputi beberapa hal seperti memberikan pelayanan informasi yang mudah diterima. Informasi dari awal hingga akhir, seperti informasi proses pendaftaran, produk paket yang ditawarkan, informasi kapan diadakan bimbingan atau manasik, informasi apa saja yang perlu dipersiapkan, informasi kapan pemberangkatan dan informasi kapan pemulangan.

Memahami proses pencarian informasi konsumen sangat penting bagi operator tur dan bidang keputusan strategis agen perjalanan, seperti perencanaan komunikasi, pengenalan produk baru, dan manajemen hubungan pelanggan. Berdasarkan analisis deskriptif, ini menunjukkan bahwa pelancong Umrah memilih teman dan kerabat, dan pengalaman pribadi sebagai dua sumber informasi internal yang paling penting. Jenis sumber informasi ini diyakini dapat memberikan informasi terperinci tentang paket wisata Umrah dan Ziarah untuk Mekah dan Madinah. Kriteria kualitas sumber-sumber informasi ini harus mudah diambil,

${ }^{33}$ Rustika Atmawati, Analisis Pengaruh Kualitas Pelayanan Terhadap Kepuasan Konsumen Pada Matahari Departement Store Di Solo Grand Mall, Surakarta: Universitas Muhammadiyah Surakarta, Daya Saing Jurnal Ekonomi Manajemen Sumber Daya Vol. 5, No. 1, Juni 2004. 
cepat diakses, mudah dipahami, kredibel, dapat diandalkan, dan memadai. ${ }^{34}$

PT. Makkah Multazam Safir tidak hanya memberikan informasi saja, akan tetapi jika ada keluhan-keluham terhadap apapun bentuknya mulai dari tanah air sampai tanah suci Makkah, jamaah umroh atau haji bisa langsung berkomunikasi kepada Multazam ataupun Tour Leader ${ }^{35}$ disana. Semua informasi disampaikan baik dan agar persiapan tata cara beribadah dapat dilaksanakan dengan baik agar tidak terjadi miscomunication.

Analisis jenis ini pelayanan dalam kelengkapan administrasi menjadi sangat penting. Kelengkapan administrasi dengan layanan yang baik disesuaikan dengan paket yang PT. Makkah Multazam Safir tawarkan. Calon jamaah haji dan umroh merasakan dengan persyaratan administrasi yang mudah dengan pelayanan yang baik dan dapat diterima. Memberikan pelayanan dengan perkenalan yang baik dari awal administrasi menjadikan kualitas mutu yang diberikan menjadi jaminan jamaah akan balik lagi ke travel ini. Kemudian masih ada beberapa yang menjadi sebuah perbedaan di dalam bidang pelayanan yang ditawarkan oleh PT Makkah Multazam Safir jika dibandingkan dalam salah satu proses administrasi yaitu mendampingi dibuatkannya Paspor secara langsung dikarenakan blangko pembuatan paspor migrasi tersedia di kantor Multazam.

Analisis berikutnya adalah Analisis Jaminan (Insurance). Petugas atau pembimbing dimaksudkan mempunyai pengetahuan baik yang menyangkut (ilmu pengetahuan) dan pengalaman lapangan tentang pelaksanaan ibadah haji dan umroh. Dari mulai persiapan keberangkatan sampai pada pelaksanaanya ditanah suci. Multazam telah menyiapkan ustad dan ustadzah yang handal dan berpengalaman dan disiapkan Tour Leader dan Muthoif (Tour Guide). Tipe analisis jaminan, penting juga untuk mengantisipasi apabila ada jamaah yang harus dirawat kerumah sakit. Apabila ada jamaaah yang sakit dan harus dirawat kerumah sakit, maka PT. Makkah Multazam Safir tidak akan lepas tangan begitu saja.

Analisis berikutnya adalah Analisis Bukti Fisik (Tangibles). Pada analisis ini kelengkapan fasilitas dan dan fungsi sarana menjadi salah satu perhatian, sehingga penyelenggara travel memberikan kelengkapan pendukung dan penunjang. Analisis ini juga sangat berkaitan dengan kebersihan dan kerapihan tempat Hotel jamaah Haji \& umroh. Tempat Hotel dekat dengan pusat ibadah menjadi perhatian lain yang menjadi pertimbangan oleh pihak konsumen. Perlengkapan adalah faktor penting bagi jamaah haji dan umroh seperti buku panduan perjalanan, Manasik \& Headset adalah salah satu perlengkapan yang harus dimiliki oleh para jamaah haji dan umroh, agar mereka mengikuti dan membaca pada waktu bimbingan dan pelaksanaan seputar ibadah. Perlengkapan lain seperti seragam, kain ihram dan mukena merupakan perlengkapan penunjang karena memudahkan Tour Leader dalam membimbing.

34Siti Hasnah Hassan, Determinants of Destination Knowledge Acquisition in Religious Tourism: Perspective of Umrah Travelers, Published by Canadian Center of Science and Educatio: International Journal of Marketing Studies; Vol. 7, No. 3; 2015, h. 85-91.

35Philip Kotler , 2008, Manajemen Pemasaran..., h. 285. 
Pendukung lainnya adalah transportasi selama kegiatan menggunakan bus berAC. Travel menyediakan alat transportasi dalam setiap kegiatan.

Selain beberapa analisis diatas, ada juga yang dikenal dengan Analisis Daya Tanggap (Responsiveness). Daya tanggap ${ }^{36}$ merupakan kesediaan membantu pelanggan dan memberikan jasa dengan cepat. Dalam hal ini, kecepatan pelayanan menjadi salah satu hal yang harus diperhatikan oleh perusahaan travel haji dan umroh. Misalnya, segala kebutuhan atau keperluan jemaah yang memerlukan pelayanan dari pihak travel dilaksanakan secara cepat tanpa adanya waktu tunggu yang lama bagi jemaah. Hal ini dilakukan guna menghindari keluhan dari jemaah sebagai pelanggannya.

Analisis terakhir adalah Analisis Empati (Emphathy). Memberikan keamanan dan kenyamanan pada jamaah haji dan umroh menjadi aspek yang cukup di perhatikan dalam analisis jenis ini. PT. Makkah Multazam Safir bertanggung jawab dengan apa yang telah direncanakan pada program awal, memberikan keamanan dan kenyamanan kepada para jamaah haji dan umroh agar mereka bisa beribadah dengan tenang dan tanpa adanya rasa khawatir dalam mengunjungi Baitullah. Perlunya memberikan pelayanan dan perhatian secara individu maupun kelompok dari jamaah haji dan umroh. Dan dibagian inilah yang sangat penting karena jamaah haji dan umroh akan merasa diberi perhatian PT. Makkah Multazam Safir sehingga akan lebih mengenal dan memahami kondisi jamaah haji dan umrah. Dari pelayanan yang ada, PT Makkah Multazam Safir dan Al-Madinah Tour \& Travel dianggap telah memenuhi kriteria pada beberapa analisis yang telah disebutkan.

Analisis mengenai hambatan dalam pelaksanaan sangatlah penting untuk dilakukan sehingga akan dapat meminimalisasi kesalahan dimasa mendatang. Selain itu, dari kelemahan dan hambatan yang terjadi di PT. Makkah Multazam Safir dan Al-Madinah Tour \& Travel, maka pihak pengelola harus bisa membenahi dalam penyelenggaraan umroh maupun haji, supaya para jamaah mendapatkan pelayanan dengan baik.

Produsen atau penyedia jasa harus selalu berusaha memenuhi kebutuhan dan keinginan konsumen disaat persaingan semakin ketat dengan menawarkan berbagai jenis produknya. Namun dengan adanya berbagai tawaran ini, dapat memberikan dampak berupa konsumen memiliki banyak pilihan dan kekuatan tawar-menawar konsumen semakin besar sehingga perusahaan harus senantiasa berorientasi pada kepuasan pelanggan sebagai tujuan utamanya. Oleh karena itu, perusahaan harus memiliki strategi untuk dapat memenangkan persaingannya. ${ }^{37}$

Hambatan-hambatan yang dialami oleh di PT. Makkah Multazam Safir dalam Strategi Pemasaran dan Pelayanannya adalah sebagai berikut: a) Masih kurangnya pengawasan pada tahap pelaksanaan, b) Pelayanan yang masih membutuhkan sumber daya manusia (SDM) yang handal dibidangnya, c)

36Devi Noviyanti, Pentingnya Implementasi Strategi Pemasaran Bagi Travel Haji dan Umroh di Banjarmasin, Alhadharah Jurnal Ilmu Dakwah Vol.14 No.28, Juli-Desember 2015, h. 47.

37Ibid., h. 20. 
Inovasi program yang dilakukan PT. Makkah Multazam Safir sudah banyak dilakukan Travel lain, d) Munculnya pesaing Tour \& Travel baru menghadapi persaingan diantara travel lain.

\section{E. Simpulan}

Dari kedua bahan pembahasan materi analisa tersebut, maka dapat ditarik sebuah kerangka bahwasanya secara keseluruhan yang dilakukan oleh setiap badan usaha terkhusus seperti pelayanan ibadah haji dan umroh harus memperhatikan standarisasi ketentuan berbagai instansi negara. Selebihnya dilakukan dalam menentukan sebuah kebijakan dan penawaran produk yang berimbang dan bersaing dengan tidka saling menggesek serta men-jutsment pihak-pihak terkait dengan asumsi untuk mendapatkan prestis seperti yang diharapkan. Karena keberangkatan jamaah dan kepulangan jamaah akan membawa sebuah keterharuan tersendiri dalam harapan dan doa. Ini semua akan tercipta dan terlaksana jikalau seluruh sistem dalam managemen berjalan sebagaimana mestinya sesuai dengan fungsinya masing-masing.

\section{Referensi:}

Abdurrahman, Moeslim. 2009. Haji, Turisme, dan Pencarian Kesalehan. Jambi: IAIN Sultan Thaha Saifuddin.

Asnawi, Nur. Pemasaran Syariah Teori, Filosofi dan Isu-Isu Kontemporer. Jakarta: Rajawali Pers

Atmawati, Rustika. 2004. Analisis Pengaruh Kualitas Pelayanan Terhadap Kepuasan Konsumen Pada Matahari Departement Store Di Solo Grand Mall. Surakarta: Universitas Muhammadiyah Surakarta.

Chaermaya, Andi. 2017. Strategi Bisnis Haji PT. Arminareka Perdana (Studi Perekrutan Jamaah). Makassar: UIN Alauddin.

Departemen Agama RI. 2005. Al-Qur'an dan Terjemahnya. Jakarta: CV Diponegoro.

Dias, Agita Puspa. 2017. Manajemen Risiko Pada Industri Layanan Jasa Di Pt. Rama Mustika Agen Travel Haji Dan Umrah. Bandung: Institut Teknologi Bandung.

Edwinar, Della. 2015. Status Hukum Dana Talangan Haji Bagi Calon Jamaah Haji. Malang: Universitas Brawijaya,.

Faisol, Sanapiah. 1992. Format-format Penelitian Sosial. Jilid 1, Jakarta: Rajawali Press.

Gasperz. 2008. Marketing. Third Edition, USA: Richard D. Irwin.

Hadi, Sutrisno. 1995. Metodologi Research. Yogyakarta : Andi Offset.

Hassan,Siti Hasnah. 2015. Determinants of Destination Knowledge Acquisition in Religious Tourism: Perspective of Umrah Travelers. Published by Canadian Center of Science and Education: International Journal of Marketing Studies.

J Moleong, Lekxy. 2003. Metodologi Peneltian Kualitatif. Bandung: Remaja Rosdakarya.

Kasmir. 2005. Etika Customer Service. Jakarta: PT. Raja Grafindo Persada.

Kotler, Philip. 2008. Manajemen Pemasaran. Edisi 1 dan 2. Jakarta: Prenhallindo.

Mathew and Huberman. 1992. Analisis Data Kualitatif, Jakarta : Universitas Indonesia. 
Mulyadi, Mohammad. 2011. Penelitian Kuantitatif Dan Kualitatif Serta Pemikiran Dasar Menggabungkannya. Jurnal Studi Komunikasi Dan Media, Jakarta: Kementrian Komunikasi dan Informatika.

Noviyanti,Devi. 2015. Pentingnya Implementasi Strategi Pemasaran Bagi Travel Haji dan Umroh di Banjarmasin. Alhadharah Jurnal Ilmu Dakwah.

Nuri,Muhammad. 2014. Pragmatisme Penyelenggaraan Ibadah Haji Di Indonesia. Malaysia: University of Malay.

Oktora, Kiki dan Achyar, Adrian. 2014. The Effect of PostPurchased Perceived-Value towards the Relationship Quality of Hajj and Umrah Travel Agencies in Indonesia, The South East Asian Journal Of Management.

S. Peter, Chandler. 2009. Managing Problems Loans. Seattle.

Samuelson. 2003. Marketing orientation. Prentice Hall Cliffs, New Jersey.

Sari, Anggita Ning Tyas. 2015. Pertanggung Jawaban Hukum Terhadap Pelaksanaan Perjanjian Pemberangkatan Ibadah Haji Antara Biro Penyelenggara Ibadah Haji Khusus Dengan Calon Jamaah Haji Plus (Studi Kasus di PT. Nur Ramadhan Wisata Cabang Yogyakarta). Surakarta: Universitas Muhammadiuyah Surakarta.

Sayudi, Muhammad Yusuf. 2013. Analisis Strategi Bauran Pemasaran Haji \& Umrah Pada Pt. Nratour \& Travel Jakarta Selatan. Jakarta: Uin Jakarta.

Septarini, Dina Fitrisia. 2017. The correlation of the value of amanah and islamic pricing theory with customer satisfaction and its implication on customer loyalty in hajj and umrah service products in surabaya, Journal of Islamic Financial Studies.

Steband JR, Golt. 2008. Marketing performance Management in Organization. Revision Edition, Boston: Mas Hougton Mifflin Company.

Tania, Ajeng. 2014. Analisis Program Pelayanan Jamaah Haji dan Umroh PT. Arminareka Perdana. Jakarta: UIN Syarif Hidayatullah.

Trinkler. 2008. Marketing and Strategy in Marketing. Canada: McMIllan.

Yustifa, Nadiah dan Yulianto,Edy. 2017. Pengaruh Experiential Marketing Dan Word Of Mouth Terhadap Loyalitas Pelanggan (Survei pada konsumen PT Alhamdi Global Wisata periode umrah 2015 sampai dengan Juni 2017). Malang: Jurnal Administrasi Bisnis (JAB) | Vol. 57 No. 1

http:/ / labbaik.id/perbedaan-haji-plus-dengan-haji-reguler-untuk-jemaah-haji https://www.cnnindonesia.com/nasional/2017 